
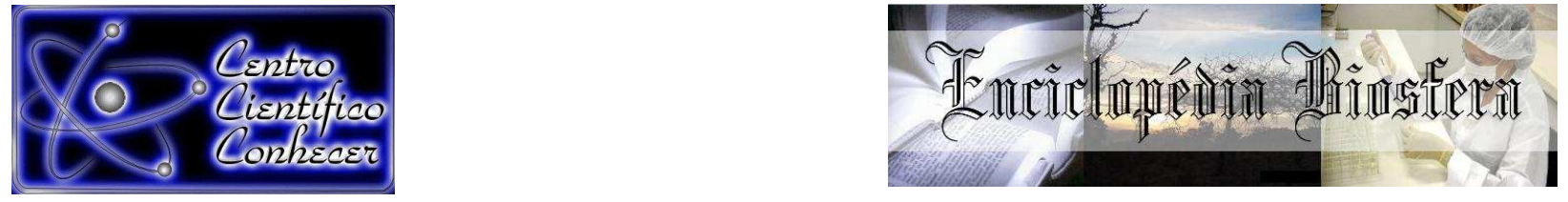

\title{
AVALIAÇÃO DA QUALIDADE DO LEITE "IN NATURA", PASTEURIZADO E ESTERILIZADO (UHT), COMERCIALIZADO EM BARRA DO BUGRES-MT
}

\author{
Karen Luiza Rocha ${ }^{1}$, Aline Pedrosa de Oliveira ${ }^{2}$, José Wilson Pires \\ Carvalho ${ }^{3}$ \\ 1 Discente do Curso de Engenharia de alimentos, Faculdade de Arquitetura e \\ Engenharia, Universidade do Estado de Mato Grosso - UNEMAT, Barra do \\ Bugres, Mato Grosso, Brasil \\ 2 Docente, Mestre, Faculdade de Arquitetura e Engenharia, \\ Departamento de Engenharia de Alimentos, Universidade do Estado de Mato \\ Grosso - UNEMAT, Barra do Bugres, Mato Grosso, Brasil \\ 3 Docente, Doutor, Faculdade de Arquitetura e Engenharia, \\ Departamento de Engenharia de Alimentos, Universidade do Estado de Mato \\ Grosso - UNEMAT, Barra do Bugres, Mato Grosso, Brasil \\ *Endereço para correspondência: iwilsonc@unemat.br \\ Recebido em: 08/04/2016 - Aprovado em: 30/05/2016 - Publicado em: 20/06/2016 \\ DOI: 10.18677/Enciclopedia_Biosfera_2016_010
}

\begin{abstract}
RESUMO
Sabe-se que a qualidade do leite consumido no país é uma constante preocupação dos técnicos e autoridades ligadas à área de saúde e laticínios. Desta forma, objetivou-se com o presente estudo avaliar a qualidade físicoquímica e microbiológica dos tipos de leite "in natura", pasteurizado e esterilizado comercializados (UHT- ultra high temperature) comercializados na cidade de Barra do Bugres. As coletas foram realizadas semanalmente, durante 3 semanas, totalizando 33 amostras, as quais passaram por análises físico-químicas (acidez em graus Dornic, pH, identificação de amido, teste de estabilidade em álcool, atividade de peroxidase e peróxido de hidrogênio) e por análise microbiológica de detecção de coliformes termotolerantes. As amostras de leite, mostraram-se $100 \% \mathrm{em}$ acordo com a legislação vigente para as análises de acidez, identificação de amido, peroxidase e peróxido de hidrogênio. Com relação a análise de estabilidade ao álcool, 33,33\% das amostras analisadas mostraram-se instáveis. $\mathrm{Na}$ análise de coliformes termotolerantes, apenas as amostras de leite UHT A e UHT B estavam dentro dos padrões vigentes. De acordo com os presentes resultados conclui-se que, das amostras analisadas praticamente todas se apresentaram dentro dos limites determinados pela legislação vigente. Entretanto, sugere-se uma maior e mais rigorosa fiscalização por meio dos órgãos públicos para que 0 consumidor tenha a garantia de um produto de qualidade.
\end{abstract}

PALAVRAS-CHAVE: acidez, coliformes termotolerantes, físico-química 


\title{
MILK QUALITY ASSESSMENT "IN NATURA", PASTEURIZED AND STERILIZED (UHT), MARKETED IN BARRA DO BUGRES-MT
}

\begin{abstract}
It is known that the quality of the milk consumed in the country is a constant concern of technicians and officials linked to health and dairy area. Thus, the aim of the present study was to evaluate the physicochemical and microbiological quality of types of milk "in natura", pasteurized and sterilized marketed (UHT- ultra high temperature) commercialized in the city of Barra do Bugres. Samples were collected weekly for 3 weeks, totalling 33 samples, which have underwent physical and chemical analysis (acidity Dornic degrees, $\mathrm{pH}$, starch identification, stability test for alcohol, peroxidase activity and hydrogen peroxide) and microbiological analysis detection of fecal coliforms. The milk samples, proved to be $100 \%$ in accordance with current legislation for acidity analysis, starch identification, peroxidase and hydrogen peroxide. Regarding the analysis of alcohol stability, $33.33 \%$ of the samples showed to be unstable. On the analysis of fecal coliforms, only samples of UHT milk UHT A and $B$ were within the current standards. According to the present results it is concluded that the samples had virtually all within the limits set by law. However, it suggests a larger and more rigorous enforcement by public bodies so that the consumer has the guarantee of a quality product.
\end{abstract}

KEYWORDS: thermotolerant coliform, physical-chemistry, acidity.

\section{INTRODUÇÃO}

A pecuária leiteira brasileira é um ramo de grande importância econômica para várias regiões brasileiras. Além disso, o leite se destaca por ser um alimento de alto valor nutritivo, sendo fonte de proteína, lipídeos, açúcares, sais minerais e vitaminas, podendo ser considerado um alimento completo (ROBIM et al., 2012; NETO et al. 2014).

A qualidade do leite consumido no país é uma constante preocupação para saúde publica e a indústria. Acerca desta afirmação o Ministério da Agricultura, Pecuária e Abastecimento (MAPA) publicou no Diário Oficial da União de 29 de dezembro de 2011, a Instrução Normativa n‥ 62 (IN 62), que regulamenta o padrão de produção, identidade e qualidade do leite, incluindo manejo de ordenha, resfriamento na propriedade, transporte a granel, parâmetros físico-químicos, microbiológicos e contagem de células somáticas, o que aumentou o nível de exigência nas propriedades e nas indústrias (BRASIL, 2011).

A obtenção de leite de qualidade adequada ao consumo humano em termos nutricionais e de segurança alimentar, depende, cada vez mais, de um processo de produção controlado e monitorado em todas as etapas, desde a formação do rebanho, ordenha até a chegada no âmbito industrial e por fim, a comercialização do mesmo (EMBRAPA, 2013).

Desta forma, objetivou-se com o presente estudo avaliar a qualidade físico-química e microbiológica do leite "in natura", pasteurizado e esterilizado comercializados em Barra do Bugres, Mato Grosso, com o intuito de detectar se os tipos de leites estão aptos para o consumo humano segundo o preconizado pelas normas vigentes. 


\section{MATERIAL E METODOS}

Foram realizadas as análises físico-químicas e microbiológica em três lotes de uma marca de leite pasteurizado, duas marcas de leite esterilizado (UHT), ambos provenientes do comércio local; e de dois fornecedores de leite cru localizados na região norte da cidade de Barra do Bugres-MT. Realizou-se três coletas, com intervalo de uma semana entre elas, a cada coleta foram obtidas três amostras do mesmo lote, para os leites pasteurizado e UHT, totalizando três lotes avaliados, e uma amostra de leite cru foi obtida em cada coleta.

Todas as amostras foram analisadas em triplicata, nas análises físicoquímicas para maior confiabilidade nos resultados e os mesmos foram reportados como média \pm desvio padrão. A avaliação dos resultados da análise microbiológica foi feita pelo teste de Tukey, com probabilidade de 5\% (Statistica 7.0), com o intuito de realizar a análise comparativa entre as médias obtidas dos diferentes tipos leite.

\section{Análises físico-químicas}

Foram realizadas as análises físico-químicas de $\mathrm{pH}$, acidez, teste do álcool, teste de peroxidade, detecção de amido e detecção de peróxido de hidrogênio, no laboratório de química da Universidade do Estado de Mato Grosso, campus de Barra do Bugres, seguindo os métodos descritos pelo INSTITUTO ADOLFO LUTZ (2008) e Instrução Normativa № 68 (BRASIL, 2006).

\section{Análise de $\mathrm{pH}$}

Para a medição do $\mathrm{pH}$, utilizou-se um pHmetro (potenciômetro) devidamente calibrado com solução tampão 4,0 e 7,0, seguindo as instruções do manual do fabricante. Para a realização das seguintes medidas usou-se 15 $\mathrm{mL}$ da amostra de leite sem diluição. Tais medidas foram usadas para verificar existência de processo de fermentação do leite em estudo (ADOLFO LUTZ, 2008).

\section{Análise de Acidez}

A acidez foi determinada usando-se $10 \mathrm{~mL}$ da amostra com a adição de 3 gotas da solução de fenolftaleína a $1 \%$ e titulado com solução de hidróxido de sódio $0,1 \mathrm{~N}$, padronizada, até aparecimento da coloração (ADOLFO LUTZ, 2008). Além disso, foi usado o seguinte cálculo para transformação da acidez

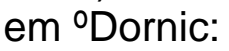

Acidez (Dornic) $=\mathrm{V} \times f \times 0,9 \times 10$

Onde: em mL;

$\mathrm{V}$ = volume da solução de hidróxido de sódio $0,1 \mathrm{~N}$ gasto na titulação,

$\mathrm{f}$ = fator de correção da solução de hidróxido de sódio $0,1 \mathrm{~N}$;

0,9 = fator de conversão do ácido lático;

10 = transformação de ácido lático para grau Dornic.

\section{Identificação de amido}

Foi medido $9 \mathrm{~mL}$ da amostra de leite em uma proveta e em seguida transferido para um béquer e aquecido até ebulição. Em seguida a amostra foi 
resfriada e adicionado 2 gotas de solução de Lugol. A aparição de uma coloração azul indica a presença de amido (ADOLFO LUTZ, 2008).

\section{Prova de peroxidase}

Transferiu-se $10 \mathrm{~mL}$ da amostra para um tubo de ensaio de $15 \mathrm{~mL}$, e aquecido em banho-maria a $(43 \pm 2)^{\circ} \mathrm{C}$ por 5 minutos. Na capela, foi adicionado $2 \mathrm{~mL}$ da solução de guaiacol e 3 gotas de peróxido de hidrogênio. A formação de uma coloração salmão indicou peroxidase positiva (ADOLFO LUTZ, 2008).

\section{Estabilidade ao etanol a $68 \%$ (teste do álcool)}

Esta analise consiste na mistura de $3 \mathrm{~mL}$ de leite e $3 \mathrm{~mL}$ de álcool $68 \%$ (v/v), seguido por agitação, se houver floculação/formação de grumos do leite, sugere-se que o leite não é estável ao aquecimento (ADOLFO LUTZ, 2008).

\section{Identificação de peróxido de hidrogênio}

Foi transferido $9 \mathrm{~mL}$ da amostra para um tubo de ensaio de $15 \mathrm{~mL}$ e em seguida foi adicionado $2 \mathrm{~mL}$ de uma solução de guaiacol a $1 \%$ e $2 \mathrm{~mL}$ de leite cru. O surgimento da cor salmão indicou a presença de peróxido de hidrogênio (ADOLFO LUTZ, 2008).

\section{Análise microbiológica}

A detecção de coliformes termotolerantes foi realizada pelo método APHA DO NÚMERO MAIS PROVÁVEL (NMP), de acordo como descrito por SILVA et al. (2010).

Para tanto, $25 \mathrm{~mL}$ da amostra de leite foi inoculada em $225 \mathrm{~mL}$ de água peptonada $0,1 \%$, para a realização da diluição $10^{-1}$, em seguida uma alíquota de $1 \mathrm{~mL}$ foi transferido para tubo contendo $9 \mathrm{~mL}$ de água peptonada $0,1 \%$ para realizar a diluição $10^{-2}$ e posteriormente $1 \mathrm{~mL}$ da diluição $10^{-2}$ será transferido para outro tubo contendo $9 \mathrm{~mL}$ de água peptonada $0,1 \%$, sendo essa diluição $10^{-3}$

Para a realização do teste presuntivo, cada uma das diluições previamente preparadas, foram inoculadas em uma série de três tubos contendo $10 \mathrm{~mL}$ de caldo lauril sulfato triptose (LST), adicionando-se $1 \mathrm{~mL}$ da diluição por tubo de LST, e incubando a $35 \pm 0,5{ }^{\circ} \mathrm{C} / 24 \pm 2 \mathrm{~h}$. Após o período de incubação foi realizada a leitura onde os resultados positivos foram observados pelo crescimento e produção de gás.

Para a confirmação e contagem de coliformes termotolerantes, dos tubos de LST com produção de gás, transferiu-se uma alçada bem carregada para tubos de caldo E.coli (EC) e incubado por $24 \pm 2$ horas em banho maria a $45,5 \pm 0,2 \stackrel{\circ}{\circ} \mathrm{C}$. A determinação do número mais provável por $\mathrm{mL}$, foi obtido anotando-se o número de tubos de EC com produção de gás, confirmativo da presença de coliformes termotolerantes e comparando os resultados observados com a tabela de NMP. 


\section{RESULTADOS E DISCUSSÕES}

\section{Análise da qualidade físico-química do leite esterilizado (UHT), pasteurizado e in natura.}

$\mathrm{Na}$ Tabela 1 são apresentados os resultados de $\mathrm{pH}$, acidez ( $\left.{ }^{\circ} \mathrm{D}\right) \mathrm{e}$ estabilidade ao álcool, para diferentes lotes de leite in natura, pasteurizado, UHT, coletados em cidade de Barra do Bugres. Os valores de acidez em grau Dornic encontrados para do leite UHT e pasteurizado estão no intervalo de $15,14 \pm 0,02$ a $16,78 \pm 0,63 \stackrel{\circ}{ } \mathrm{D}$, enquanto que a acidez para o leite in natura apresenta valores na faixa de $14,25 \pm 1,26$ a $18,71 \pm 1,26 \stackrel{\circ}{ } \mathrm{D}$, respectivamente (Tabela 1). De acordo com a Instrução normativa no 62 de 2011, o índice de acidez em graus Dornic considerado normal para o leite pode variar de 14 a $18^{\circ} \mathrm{D}$, considerando o erro experimental (BRASIL, 2011). Assim, os lotes analisados apresentaram acidez ( $\left.{ }^{\circ} \mathrm{D}\right)$ em conformidade.

Esses estudos de qualidade do leite são importantes, tendo em vista que resultados reportados por OLIVEIRA E SANTOS (2012) de acidez de leites pasteurizado, provenientes dos municípios da região do Vale do JaguaribeCeara, constataram que $85 \%$ das amostras apresentaram valores fora dos padrões em relação à acidez, mostrando-se alcalinas. De acordo com os autores, tais resultados podem ser justificados possivelmente devido à adição de água ao mesmo. Nesse sentido, estudos de caracterização físico-química de leite pasteurizado no estado de Alagoas, verificaram que das amostras analisadas, 7,5\% delas, apresentaram-se com acidez Dornic fora dos padrões da legislação. Os autores sugerem que esses resultados indicam que, provavelmente, não houve uma refrigeração imediata logo após a pasteurização, ou ainda falhas na higiene durante a produção (SILVA et al. 2008).

TABELA 1: Parâmetros Físico-Químicos das amostras de leite esterilizado, pasteurizado e in natura comercializados na cidade de Barra do Bugres, MT.

\begin{tabular}{|c|c|c|c|c|}
\hline $\begin{array}{l}\text { Tipos de } \\
\text { leite }\end{array}$ & Lote & Acidez (ํD) & $\mathrm{pH}$ & $\begin{array}{l}\text { Estabilidade ao álcool } \\
\text { № de amostras (\%) }\end{array}$ \\
\hline \multirow{3}{*}{$\operatorname{UHT}(A)$} & Lote 1 & $15,42 \pm 0,44$ & $6,59 \pm 0,02$ & $3(100 \%)$ \\
\hline & Lote 2 & $15,74 \pm 0,15$ & $6,73 \pm 0,02$ & $3(100 \%)$ \\
\hline & Lote 3 & $15,29 \pm 0,21$ & $6,68 \pm 0,10$ & $3(100 \%)$ \\
\hline \multirow{3}{*}{ UHT (B) } & Lote 1 & $15,14 \pm 0,15$ & $6,60 \pm 0,03$ & $3(100 \%)$ \\
\hline & Lote 2 & $16,18 \pm 0,63$ & $6,41 \pm 0,42$ & $3(100 \%)$ \\
\hline & Lote 3 & $15,14 \pm 0,02$ & $6,67 \pm 0,03$ & $3(100 \%)$ \\
\hline \multirow{3}{*}{ Pasteurizado } & Lote 1 & $15,14 \pm 0,21$ & $6,57 \pm 0,01$ & $3(100 \%)$ \\
\hline & Lote 2 & $15,59 \pm 0,52$ & $6,41 \pm 0,42$ & $3(100 \%)$ \\
\hline & Lote 3 & $16,78 \pm 0,63$ & $6,66 \pm 0,06$ & $2(76,7 \%)$ \\
\hline \multirow{3}{*}{ In natura $\mathrm{A}$} & Lote 1 & $14,56 \pm 0,14$ & $6,83 \pm 0,17$ & $3(100 \%)$ \\
\hline & Lote 2 & $14,25, \pm 1,26$ & $6,82 \pm 0,01$ & $3(100 \%)$ \\
\hline & Lote 3 & $17,82 \pm 0,17$ & $6,71 \pm 0,04$ & $3(100 \%)$ \\
\hline \multirow{3}{*}{ In natura $\mathrm{B}$} & Lote 1 & $15,14 \pm 0,15$ & $6,78 \pm 0,08$ & $3(100 \%)$ \\
\hline & Lote 2 & $17,82 \pm 0,17$ & $6,70 \pm 0,01$ & $3(100 \%)$ \\
\hline & Lote 3 & $18,71 \pm 1,26$ & $6,63 \pm 0,01$ & $3(100 \%)$ \\
\hline
\end{tabular}


Dentre os lotes dos diferentes tipos de leite analisados, somente 0 segundo lote do leite UHT(B) e pasteurizado apresentou valor fora dos padrões considerado normal (Tabela 1), que compreende a faixa de 6,6 a 6,8

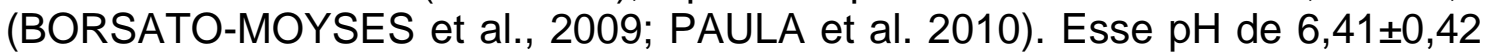
pode estar associado a fatores como: ordenha de vacas no inicio da lactação, início de processo de fermentação ou até mesmo influenciado pela dieta das vacas em lactação (SILVA et al. 2008; BORSATO-MOYSÉS et al. 2009; FERNANDES et al. 2013).

Os demais lotes dos diferentes tipos de leite analisados apresentaram valores de $\mathrm{pH}$ dentro da faixa considerado normal (Tabela 1), estando de acordo com o reportado por PAULA et al. (2010). BORSATO-MOYSÉS et al. (2009) analisaram $\mathrm{pH}$ para determinação da qualidade do leite em Tangara da Serra-MT, sendo observado que $75 \%$ das amostras analisadas mostram-se fora das condições consideradas normais. Por outro lado, PAULA et al. (2010) realizaram análises físico-químicas em leite cru, provenientes de propriedades leiteiras da região Sul Fluminense e foi constatado que, 100\% das amostras analisadas apresentaram $\mathrm{pH}$ dentro do recomendado. A avaliação da acidez $\mathrm{e}$ do $\mathrm{pH}$ são parâmetros importantes a serem avaliados uma vez que podem ser um indicador da qualidade sanitária e estabilidade térmica do leite.

Com base nos resultados da análise de estabilidade ao álcool (Tabela 1, coluna 5), as amostras de leite UHT, in natura apresentaram caseína estável. No entanto, as amostras pertencentes ao lote 3 do leite pasteurizado, conforme pode ser observado na Figura 1, apresentaram formação de grumos, indicando a instabilidade ao álcool. Estas análises são úteis para atestar a estabilidade térmica do leite, predizendo a estabilidade do mesmo a tratamentos térmicos, tal como a pasteurização e a ultrapasteurização (NETO et al., 2014).

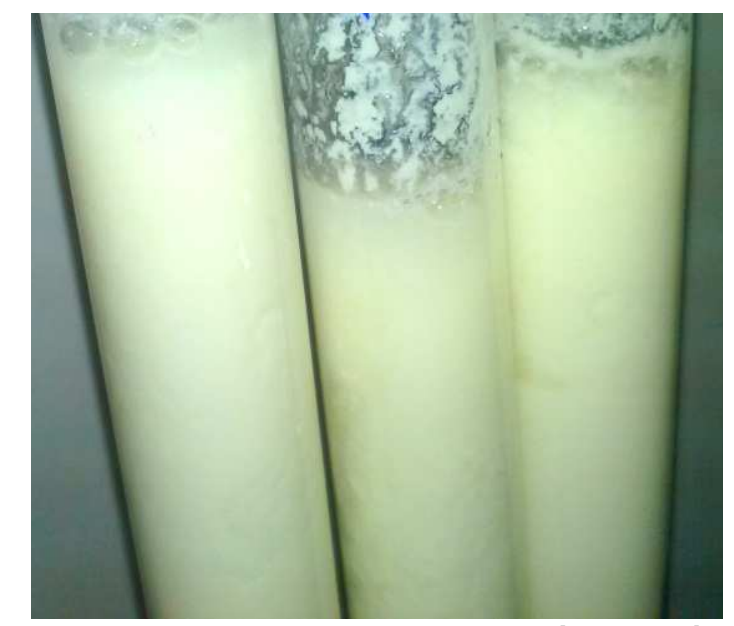

FIGURA 1 - Amostra de leite instável ao álcool.

A instabilidade da caseína ao álcool e ao calor pode ocorrer devido a acidificação do leite pelo crescimento de microrganismos, o que não foi observado nas amostras em questão, uma vez que esta apresentou acidez Dornic e pH no intervalo considerados normais. Entretanto, a instabilidade da caseína pode ser também influenciada por desequilíbrio iônico, variação de temperatura e principalmente relacionado a concentração de minerais como o cálcio e fósforo que por sua vez pode ser influenciados pela dieta do rebanho leiteiro (OLIVEIRA, et al. 2007; FERNANDES, et al. 2013; COSTA et al., 2014). 
A Tabela 2 mostra os resultados do teste de detecção de amido, peroxidase e peróxido de hidrogênio, para o leite UHT, pasteurizado e in natura. De acordo com os limites estabelecidos na Instrução Normativa № 68 (BRASIL, 2011), todos as amostras de leites apresentam resultado de acordo 0 exigido por esta normativa.

Nos estudos realizados por JÚNIOR et al. (2013) de análise da enzima peroxidase em amostras de leite cru coletadas na região de Ivaiporã, Paraná, notou-se que todas as amostras estavam de acordo com os parâmetros exigidos pela legislação, ou seja, o leite cru apresentou resultado positivo para esta enzima. A avaliação da presença da peroxidase é importante em leite in natura, quando a matéria prima é recebida na industria, como parâmetro de verificação se o leite foi submetido a tratamento térmico a $80^{\circ} \mathrm{C}$ ou a temperatura superior, tendo em vista que esta enzima sofre desnaturação a esta temperatura. Esse teste é também usado para identificar falha no tratamento térmico de leite pasteurizado, permitindo a constatação de superaquecimento ou prolongamento excessivo do tempo de aquecimento, devendo a peroxidase permanecer ativa neste tipo de leite. Por outro lado, a verificação da enzima em leite UHT é usado como parâmetro de eficiência do tratamento térmico, uma vez que a mesma é termoresistente, sendo inativada com a elevação de temperaturas, e sua ausência no leite esterilizado aponta que o leite atingiu temperatura adequada (JÚNIOR et al. 2013).

TABELA 2: Parâmetros Físico-Químicos das amostras de leite esterilizado, pasteurizado e in natura comercializados na cidade de Barra do Bugres, MT.

\begin{tabular}{|c|c|c|c|c|}
\hline $\begin{array}{l}\text { Classes de } \\
\text { leite }\end{array}$ & Lotes & $\begin{array}{l}\text { Presença de } \\
\text { Peroxidase }\end{array}$ & $\begin{array}{l}\text { Presença de } \\
\text { Amido }\end{array}$ & $\begin{array}{l}\text { Presença de } \\
\text { Peróxido de } \\
\text { hidrogênio }\end{array}$ \\
\hline \multirow[t]{3}{*}{ UHT A } & Lote 1 & - & - & - \\
\hline & Lote 2 & - & - & - \\
\hline & Lote 3 & - & - & - \\
\hline \multirow[t]{3}{*}{ UHT B } & Lote 1 & - & - & - \\
\hline & Lote 2 & - & - & - \\
\hline & Lote 3 & - & - & - \\
\hline \multirow[t]{3}{*}{ Pasteurizado } & Lote 1 & + & - & - \\
\hline & Lote 2 & + & - & - \\
\hline & Lote 3 & + & - & - \\
\hline IN NATURA & Lote 1 & + & - & - \\
\hline \multirow[t]{2}{*}{$A$} & Lote 2 & + & - & - \\
\hline & Lote 3 & + & - & - \\
\hline \multirow[t]{3}{*}{ אח } & Lote 1 & + & - & - \\
\hline & Lote 2 & + & - & - \\
\hline & Lote 3 & + & - & - \\
\hline
\end{tabular}

Quanto às análises de identificação de adição de amido, 100\% das amostras atestaram-se negativas (Tabela 2). Tendo em vista que, a adição de amido no leite é um ato fraudulento, realizado com o objetivo de corrigir a densidade do leite precedido de aguagem (JÚNIOR et al. 2013).

PAULA et al. (2010) examinando o leite cru refrigerado proveniente da região Sul Fluminense, verificaram que nas amostras analisadas não foi 
observado a presença de amido. Ainda, CAMPOS et al. (2011) em estudos semelhantes realizados com leites produzidos na região de Brasília também não observaram nenhuma fraude por adição de amido nas amostras analisadas, de leite pasteurizado integral.

Todas as amostras avaliadas quanto a presença de peróxido de hidrogênio apresentaram resultado negativo (Tabela 2). Resultados semelhantes aos observados por ROSA et al. (2015) ao analisarem a presença peróxido de hidrogênio em lotes de leite ultra-pasteurizado comercializado no município de Erechim - RS, não encontrando nenhuma amostra positiva para essa substância. Em tais estudos observou-se também a ausência de peróxido de hidrogênio nos lotes analisados.

Estes resultados são bastante positivos para os diferentes tipos de leite comercializados na cidade de Barra do Bugres-MT, uma vez que a adição de peróxido de hidrogênio é considerada uma fraude grave por mascarar a qualidade higiênica do leite, tendo em vista que esta substância inibi o crescimento de microrganismos, evitando a acidificação do leite, prolongando consequentemente a vida útil do produto.

\section{Análise de qualidade microbiológica do leite esterilizado (UHT), pasteurizado e in natura.}

A qualidade microbiológica dos tipos de leite testado foi avaliada pela contagem de coliformes termotolerantes. $\mathrm{Na}$ Tabela abaixo, estão representados os resultados médios da contagem de coliformes termotolerantes (CT), das categorias de amostras de leite cru (in natura), pasteurizado e esterilizado, e comparados conforme a RDC №12 (BRASIL, 2001).

TABELA 3: Média da contagem de coliformes termotolerantes em amostras de leite in natura, pasteurizado e esterilizado (UHT), comercializadas em Barra do Bugres, MT.

\begin{tabular}{llll}
\hline TIPOS DE LEITE & $\begin{array}{l}\text { No } \\
\text { Amostras }\end{array}$ & $\begin{array}{l}\text { № de amostras } \\
\text { positivas }(\%)\end{array}$ & $\begin{array}{l}\text { MÉDIA } \\
\text { (NMP/mL) }\end{array}$ \\
\hline UHT A & 9 & $3(33,3)$ & $2,95^{\mathrm{a}} \mathrm{NMP} / \mathrm{mL}$ \\
UHT B & 9 & $3(33,3)$ & $3,35^{\mathrm{a}} \mathrm{NMP} / \mathrm{mL}$ \\
PASTEURIZADO & 9 & $4(44,4)$ & $6,9^{\mathrm{a}} \mathrm{NMP} / \mathrm{mL}$ \\
IN NATURA A & 3 & $3(100)$ & $40,33^{\mathrm{b}} \mathrm{NMP} / \mathrm{mL}$ \\
IN NATURA B & 3 & $3(100)$ & $13^{\mathrm{a}} \mathrm{NMP} / \mathrm{mL}$ \\
\hline
\end{tabular}

Médias seguidas de letras minúsculas diferentes na mesma coluna diferem significativamente $(<0,05)$ pelo teste de Tukey.

Para análise de coliformes Termotolerantes, as médias das contagens mínimas e máximas para todos os tipos de leite, variaram entre 2,95 NMP/mL, a 40,33 NMP/mL. Os tipos de leite UHT A e UHT B apresentaram resultados de 2,95 NMP/mL e 3,35 NMP/mL respectivamente, encontrando-se dentro dos padrões determinados pela legislação. Em contrapartida, o leite pasteurizado apresentou contagem de 6,9 NMP/mL, valor acima do permitido de acordo com a RDC № 12, que estabelece limite de coliformes termotolerantes para leite pasteurizado e UHT de 4 NMP/mL. 
De acordo com MARTINS et al. (2012), a presença de termotolerantes nas amostras de leites pasteurizados indica que houve falha em alguma etapa de obtenção, processamento ou envase do leite, que evidencia a necessidade de reavaliação dessas etapas, a fim de se identificar e diagnosticar todos os focos de contaminação.

A legislação vigente não estabelece limites máximos para a presença de termotolerantes no leite in natura, no entanto, observou-se a detecção de coliformes termotolerantes em contagens elevadas nas amostras de leite in natura $\mathrm{A}(40,33 \mathrm{NMP} / \mathrm{mL})$. Nas amostras de leite in natura $\mathrm{B}$ a presença de termotolerantes foi observada em menor quantidade (13 NMP/mL), deve-se levar em consideração que dependendo da carga microbiana e das condições de armazenamento, pode ocorrer a proliferação desses microrganismos, diminuindo a qualidade final do produto.

Confrontando os resultados da análise microbiológica do leite in natura $\mathrm{A}$ com o pH (Tabela 1), pode-se observar que os leites se apresentaram alcalinos para os lotes 1 e 2, e média alta de contagem de coliformes termotolerantes, o que pode ser sugestivo de presença de mastite no rebanho, no entanto, tal confirmação necessitaria de maior investigação por meio de realização de testes como o da caneca telada, California Mastitis Test (CMT) e Contagem de Células Somáticas (CCS).

SILVEIRA \& BERTAGNOLI (2014) avaliaram a qualidade do leite cru comercializado informalmente em feiras livres no município de Santa Maria-RS, os resultados obtidos para coliformes totais apresentaram contagens acima de 102 e $103 \mathrm{NMP} / \mathrm{mL}$ em $70 \%$ e $20 \%$ das amostras analisadas, respectivamente. A presença de coliformes termotolerantes foi constatada em todas as amostras de leite cru informal, sendo que $50 \%$ destas amostras apresentaram índices acima de $102 \mathrm{NMP} / \mathrm{mL}$.

FREITAS et al. (2013) avaliaram a microbiota de leite cru, localizados nas microrregiões do Brejo (A), Sertão (B) e Cariri (C) paraibanos do estado da Paraíba. Com relação ao NMP de coliformes termotolerantes, as amostras dos produtores A e B apresentaram maior contaminação, estando pelo menos uma das amostras acima de $10^{3} \mathrm{NMP} / \mathrm{mL}$.

ALFONZO et al. (2012) analisaram 96 amostras de leite in natura, retirados de tanques de expansão, para contagem de coliformes termotolerantes. Dentre as amostras analisadas, 46,87\% apresentaram-se positivas.

SCABIN et al. (2012) em estudo sobre a qualidade microbiológica do leite in natura, verificaram que $35 \%$ das amostras de leite avaliadas estavam contaminadas por coliformes termotolerantes, o que pode ser compreendido nesta situação, que estes microrganismos são encontrados com frequência no leite cru, principalmente devido as deficiências no controle sanitário do rebanho e na higiene do processo de obtenção do leite.

Existem alguns fatores que devem ser apontados como possíveis explicações sobre os resultados obtidos na análise microbiológica dos leites da Granja 1 (in natura A) e da granja 2 (in natura B). As propriedades não possuem estrutura adequada para realização do manejo de ordenha. Nessas propriedades, a única estrutura existente é um curral de piso não cimentado, onde não se efetuava a higienização dos utensílios a ser utilizados na ordenha manual em razão de falta de água encanada e potável, tendo disponível apenas a água do rio. Deve-se levar em consideração que ao ser ordenhado, o 
leite não era refrigerado em seguida, sendo transportado em latões em temperatura ambiente, por longos períodos, para ser comercializado de forma clandestina na cidade.

A preocupação quanto à presença de coliformes termotolerantes é, principalmente, a saúde dos consumidores, podendo causar quadros de doenças entéricas (TORTORA et al. 2005). Um dos caminhos para que as falhas sejam sanadas, é a implantação de boas práticas de obtenção e manipulação higiênica do leite e treinamentos, com o intuito de conscientizar os produtores rurais e os manipuladores nos âmbitos industriais, quanto a importância da qualidade microbiológica do leite, garantindo assim a obtenção de um produto com qualidade sanitária satisfatória e que não implique em riscos para a saúde humana (LUZ et al., 2011).

\section{CONCLUSÃO}

A avaliação da qualidade dos tipos de leite in natura, pasteurizado e UHT, mediante as analises físico-químicas atestou que na sua maioria as amostras atendiam aos requisitos mínimos previstos em lei. No entanto, alguns resultados ficaram fora dos padrões exigidos para o teste de estabilidade ao álcool. Todas as amostras de leite mostraram-se ausentes de substâncias (amido e peróxido de hidrogênio) que caracterizam fraude.

Quanto a microbiológica avaliada, pode-se observar, que apenas os leites UHT A e UHT B encontraram-se dentro dos padrões microbiológicos RDC 12 (BRASIL, 2001). Já o leite Pasteurizado mostrou-se não conforme com a legislação referida; indicando contaminação após pasteurização.

Os leites in natura das Granja 1 e 2 apresentaram alta contagens de coliformes termotolerantes sugerindo higiene insatisfatória.

Os resultados tanto das análises físico-químicas quanto microbiológicas, mostraram a necessidade de maior orientação, controle e inspeção da cadeia produtiva do leite comercializado na cidade de Barra do Bugres, para que sejam detectadas e corrigidas falhas desde o momento da ordenha, transporte, beneficiamento, aplicando as boas práticas de Fabricação (BPF), higienização dos equipamentos, instalações, treinamento para os manuseadores do leite, para enfim obter um produto final seguro e de qualidade.

\section{REFERÊNCIAS}

ALFONZO, E.P.M.; POZZA, M.S.S.; ZAMBOM, M.A.; COSTA, P.B.; POZZA, P.C.; MADRONA, G.S. Caracterização microbiológica da qualidade do leite coletado em tanques de expansão. Revista do Instituto de Laticínios Cândido Tostes [online], n.388, v.67: p.48-52, 2012. Disponível em: Linkhttp://www.revistadoilct.com.br/rilct/article/view/265/275. Acesso em: 01/04/2016.

BORSATO-MOYSÉS; CARVALHO, I.F; HOFFMANN, F.L. Avaliação físicoquímica do leite pasteurizado tipo $\mathrm{c}$ produzido e comercializado na região de Tangará da Serra - MT, Brasil - estudo de caso. Revista do Instituto de Laticínios Cândido Tostes [online], v.64. n.366,p.22-27, 2009. Disponível em: Link-http://www.revistadoilct.com.br/rilct/article/view/71/77. Acesso em: 25/03/2016. 
BRASIL. Instrução Normativa no 62 de 29 de dezembro de 2011. Aprova 0 Regulamento Técnico de Produção, Identidade e Qualidade do Leite tipo A, o Regulamento Técnico de Identidade e Qualidade de Leite Cru Refrigerado, o Regulamento Técnico de Identidade e Qualidade de Leite Pasteurizado e o Regulamento Técnico da Coleta de Leite Cru Refrigerado e seu Transporte a Granel. Diário Oficial da União, Brasília, 30 dez. 2011. Seção 1, p.1-24. Disponível em: http://www.jusbrasil.com.br/diarios/33395065/dou-secao-1-3012-2011-pg-6 Acesso em: 24/03/2016.

BRASIL. Instrução Normativa no 68 de 12 de dezembro de 2006. Oficializa os Métodos Analíticos Oficiais Físico-Químicos, para Controle de Leite e Produtos Lácteos, em conformidade com o anexo desta Instrução Normativa, determinando que sejam utilizados nos Laboratórios Nacionais Agropecuários. Diário Oficial da União, Brasília, 14 dez. 2006. Seção 1, p. 8. Disponível em: http://extranet.agricultura.gov.br/sislegisconsulta/consultarLegislacao.do?opera cao=visualizar\&id=17472 Acesso em: 24/03/2016.

BRASIL. Resolução RDC no 12 - ANVISA - Agência Nacional de Vigilância Sanitária [online]. Regulamento Técnico sobre padrões microbiológicos para alimentos de 02 de janeiro de 2001. Disponível em: http://portal.anvisa.gov.br/wps/wcm/connect/a47bab8047458b909541d53fbc4c6 735/RDC_12_2001.pdf?MOD=AJPERES. Acesso em: 23/03/2016.

CAMPOS, A.A.R; ROCHA, J.E.S; BORGO, L.A; MENDONÇA,M.A. Avaliação físico-química e pesquisa de fraudes em leite pasteurizado integral tipo "C" produzido na região de Brasília, Distrito Federal. Revista do Instituto de Laticínios Cândido Tostes [online], v.66, n.379, p.30-34, 2011. Disponível em: Link- Disponível em: http://www.revistadoilct.com.br/rilct/article/view/159/167. Acesso em: 01/04/2016.

COSTA, F.F.; BRITO, M.A.V.P.; SOUZA, G.N.; PEREIRA, D.B.C.; PINTO, I.S.B.; MARTINS, M.F. Efeito da temperatura das amostras de leite na concentração de cálcio solúvel e de betacaseína: interferência no teste de estabilidade frente ao etanol. Arquivo Brasileiro de Medicina Veterinária e Zootecnia [online], n.2, v.66, p.573-578, 2014. Disponível em: http://www.scielo.br/pdf/abmvz/v66n2/34.pdf. Acesso em: 01/04/2016.

EMBRAPA. Fraude no leite: leite de qualidade $x$ qualidade de vida. Órgão oficial da associação brasileira dos criadores de girolando. Ano xv. № 88, 2013. Disponível em: https://www.infoteca.cnptia.embrapa.br/bitstream/doc/955862/1/MidiaFraudenol eitegirolando.pdf.pdf. Acesso em: 01/04/2016.

FERNANDES, R. F.; PEREIRA, A.S.; PINHO, F.L. Influência da sazonalidade em parâmetros físico-químicos do leite cru recebido por um laticínio no norte de minas gerais. Revista do Instituto de Laticínios Cândido Tostes [online], Juiz de Fora, n. 393, v. 68, p. 36-41, 2013. DOI: http://dx.doi.org/10.5935/22386416.20130033. Disponível em: Linkhttp://www.revistadoilct.com.br/rilct/article/view/34/38. Acesso em: 03/04/2016.

FREITAS, W.C.; TRAVASSOS, A.E.R; MACIEL, J.F. Avaliação microbiológica e físico-química de leite cru e queijo de coalho produzidos no Estado da Paraíba. Revista Brasileira de Produtos Agroindustriais [online], Campina 
Grande, v.15, n.1, p.35-42, 2013. Disponível em: Linkhttp://www.deag.ufcg.edu.br/rbpa/rev151/Art1515.pdf. Acesso em: 01/04/2016.

INSTITUTO ADOLFO LUTZ. Normas Analíticas do Instituto Adolfo Lutz [online]: Métodos físico-químicos para análise de alimentos. 4.ed. São Paulo: IMESP, 2008. 2 Disponível em: http://www.crq4.org.br/sms/files/file/analisedealimentosial_2008.pdf. Acesso em: 01/04/2016.

JÚNIOR, J. C. R.; BELOTI, V.; SILVA, L. C. C.; TAMANINI, R. Avaliação da qualidade microbiológica e físico-química do leite cru refrigerado produzido na região de Ivaiporã, Paraná. Revista do Instituto de Laticínios Cândido Tostes [online]. v.68, n.392, p.5-11, 2013. Disponível em: Linkhttp://www.revistadoilct.com.br/rilct/article/view/23/27.DOI:

http://dx.doi.org/10.5935/2238-6416.20130022. Acesso em: 02/04/2016.

LUZ, D. F.; BICALHO, F. A.; OLIVEIRA, M. V. M.; SIMÕES, A. R. P. Avaliação microbiológica em leite pasteurizado e cru refrigerado de produtores da região do Alto Pantanal Sul-Mato-Grossense. Revista Agrarian [online], v.4, n.14, p. 367-374, 2011. Disponível em: http://www.periodicos.ufgd.edu.br/index.php/agrarian/article/viewArticle/1232.

Acesso em: 05/04/2016.

MARTINS, J.N. SANTOS, D.C.; OLIVEIRA, E.N.A.; ALBUQUERQUE, E.M.B. Qualidade microbiológica de leites pasteurizados comercializados na cidade de Morada Nova, Ceará. Revista Verde [online], v. 7, n. 3, p. 119-123, 2012. Disponível em:

Linkhttp://www.gvaa.com.br/revista/index.php/RVADS/article/view/1210/1267.

Acesso em: 01/04/2016.

NETO, N.A.O, Oliveira, E.N.A.; Santos, D.C.; Santos, Y.MG.; Rocha, A.P.T. Avaliação físico-química e possível ocorrência de fraudes em amostras de leite comercializadas informalmente em Encanto-RN. Revista Educação Agrícola Superior, Associação Brasileira de Educação Agrícola Superior - ABEAS [online] v.29, n.2, p.64-67, 2014. Disponível em: Linkhttp://www.abeas.com.br/revista/2014.2_revista/v29n02a02.pdf.DOI: http://dx.doi.org/10.12722/0101-756X.v29n02a02. Acesso em: 01/04/2016.

OLIVEIRA, D.S.; MORAES, C.M.; ROOS, T.B.; BERMUDES, R.F.; TIMM, C.D. Ocorrência de leite com instabilidade da caseína em Santa Vitória do Palmar, RS. Revista Brasileira de Ciência Veterinária [online], v. 14, n. 2, p. 101104, 2007. Disponível em: http://www.uff.br/rbcv/ojs/index.php/rbcv/article/view/426/pdf. Acesso em: 02/04/2016.

OLIVEIRA, E.N.A., SANTOS,D.C. Avaliação da qualidade físico-química de leites pasteurizados. Revista Instituto Adolfo Lutz [online]. São Paulo, v.71, n.1, p.193-197, 2012. Disponível em: https://www.google.com.br/url?sa=t\&rct=j\&q=\&esrc=s\&source=web\&cd=1\&cad $=$ rja\&uact=8\&ved=0ahUKEwiayf6 NzLAhUCk5AKHVwVACEQFggcMAA\&url= http\%3A\%2F\%2Fses.sp.bvs.br\%2Flildbi\%2Fdocsonline\%2Fget.php\%3Fid\%3D 
3752\&usg=AFQjCNFkPN2OAJsxAcVi6TblbjA_W5gXjA\&bvm=bv.117868183,d. Y2I. Acesso em: 01/02/2016.

PAULA, F.P.d; CARDOSO, C.E.; RANGEL, M.A.C. Análise físico-química do leite cru refrigerado proveniente das propriedades leiteiras da região sul fluminense. Revista Eletrônica TECCEN, Vassouras [online], v. 3, n. 4, p. 718, out./dez., $2010 . \quad$ Disponível em: http://www.uss.br/pages/revistas/revistateccen/V3N42010/pdf/001_Analise_Fisi co_quimica.pdf. Acesso em: 01/02/2016.

ROBIM, M.S. CORTEZ, M.A.S.; SILVA, A.C.O.; FILHO, R.A.T.; GEMAL, N.H.; NOGUEIRA, E.B. Pesquisa de fraude no leite uat integral comercializado no estado do rio de janeiro e comparação entre os métodos de análises fisicoquímicas oficiais e o metódo de ultrassom. Revista do Instituto de Laticínios Cândido Tostes [online], no 389, 67: 43-50, 2012. Disponível em: Link- http://www.revistadoilct.com.br/rilct/article/view/225/235. DOI: http://dx.doi.org/10.5935/2238-6416.20120077. Acesso em: 01/01/2016.

ROSA, S.R. GARBIN, C.M.; ZAMBONI, L.; BONACINA, M.S. Avaliação da Qualidade Físico-Química do Leite Ultra Pasteurizado Comercializado no Município de Erechim - RS. Revista visa em sociedade, Instituto Federal de Educação, Ciência e Tecnologia do Rio Grande do Sul (IFRS), ErechimRS [online],v.3, n.2 p. 99-107, 2015. Disponível em: Linkhttps://visaemdebate.incqs.fiocruz.br/index.php/visaemdebate/article/view/438. DOI: http://dx.doi.org/10.3395/2317-269x.00438. Acesso em: 01/01/2016.

SCABIN, M.V; KOZUSNY-ANDREANI, D.I.; FRIAS, D.F.R. Qualidade microbiológica do leite in natura durante o processo de obtenção e após o resfriamento. Revista CES Medicina Veterinaria y Zootecnia [online], v.7, n.1, 2012. Disponível em: http://www.scielo.org.co/pdf/cmvz/v7n1/v7n1a02.pdf. Acesso em: 01/01/2016.

SILVA, N.; JUNQUEIRA, V. C. A.; SILVEIRA, N. F. A.; TANIWAKI, M. H.; SANTOS, R. F. S.; GOMES, R. A. R. Manual de métodos de análise microbiológica de alimentos e água [online]. 4. Ed. São Paulo: Livraria Varela, 2010, 624p.

SILVA, M. C. D.; SILVA, J. V. L.; RAMOS, A. C. S.; MELO, R. O.; OLIVEIRA, J. O. Caracterização microbiológica e físico-química de leite pasteurizado destinado ao programa do leite no Estado de Alagoas, Ciência e Tecnologia de Alimentos, Campinas, [online] v.28, n.1 p. 226-230, 2008. Disponível em http://www.scielo.br/scielo.php?script=sci_arttext\&pid=S0101-

20612008000100032. Acesso 05/05/2016.

SILVEIRA, M.L., BERTAGNOLLI MARIA MICHELIN. Avaliação da qualidade do leite cru comercializado informalmente em feiras livres no município de Santa Maria-RS. Revista Visa em Debate [online], v. 2, n.2, p.75-80, 2014. Disponível

em:https://visaemdebate.incqs.fiocruz.br/index.php/visaemdebate/article/view/1 35.DOI:10.3395/vd.v2i2.135. Acesso em: 08/01/2016.

TORTORA, G. J.; FUNKE, B. R.; CASE, C. L. Microbiologia. 8. ed. Porto Alegre: Editora Atheneu, 2005. 920 p. 